\title{
INFLUÊNCIA DA LUMINOSIDADE E CONCENTRAÇÃO SALINA NA PRODUÇÃO DE LIPÍDIOS E CAROTENOIDES PELA MICROALGA Dunaliella tertiolecta EM FOTOBIORREATOR AIRLIFT
}

\author{
N. C. DA FRÉ ${ }^{1,3}$, R. RECH ${ }^{2}$ e N. R. MARCÍLIO ${ }^{3}$ \\ ${ }^{1}$ Universidade Estadual do Rio Grande do Sul, Engenharia de Bioprocessos e Biotecnologia, \\ Unidade de Bento Gonçalves \\ ${ }^{2}$ Universidade Federal do Rio Grande do Sul, Instituto de Ciência e Tecnologia de Alimentos \\ ${ }^{3}$ Universidade Federal do Rio Grande do Sul, Departamento de Engenharia Química \\ E-mail para contato: niceia@enq.ufrgs.br
}

\begin{abstract}
RESUMO - A microalga Dunaliella tertiolecta é dos poucos microrganismos fotossintéticos capaz de produzir simultaneamente grandes quantidades de carotenoides e lipídios em determinadas condições de estresse ambientais, como luminosidade e concentração salina do meio de cultivo. Porém estas condições normalmente diminuem a velocidade de crescimento das microalgas. Neste trabalho foi investigado o efeito do aumento da luminosidade e da concentração salina durante os cultivos a fim de promover a maior síntese destes bioprodutos. Para isso, os cultivos foram realizados em duas fases: (1) produção de grande número de células nas condições ideais de crescimento e, posteriormente, (2) aplicação de condições de estresse salino e luminoso. Os melhores resultados foram a $30 \mathrm{klx}$, obtendo-se 1,24 \pm $0,06 \mathrm{~g} \mathrm{~L}^{-1}$ de biomassa, 5,08 $\pm 0,04 \mathrm{mg} \mathrm{L}^{-1}$ de carotenoides no meio de cultivo, correspondendo a uma concentração 4,34 $\pm 0,38 \mathrm{mg} \mathrm{g}^{-1}$ de biomassa seca, e 10,21 \pm $0,03 \%$ de lipídios na biomassa, em 210 h de cultivo.
\end{abstract}

\section{INTRODUÇÃO}

As microalgas são fontes naturais de ácidos graxos insaturados, carotenoides, xantofilas, vitaminas, proteínas, minerais e enzimas. O potencial comercial das microalgas para a produção industrial de alimentos funcionais a partir destes metabólitos é amplamente reconhecido. Consequentemente, o cultivo em massa de microalgas, visando o aumento da produção desses compostos bioquímicos, essenciais para a saúde humana, é de grande interesse prático (Inbaraj et al., 2006; Raja et al., 2007).

Os carotenoides provenientes de microalgas têm sido utilizados como aditivos alimentares na forma de corantes, antioxidantes e vitaminas e, também, nas indústrias de cosméticos e farmacêutica. $\mathrm{O}$ uso desses compostos em aplicações terapêuticas como agentes na prevenção de doenças degenerativas e do câncer e estimuladores do sistema imunológico é resultado de sua habilidade de proteção contra os radicais livres (Del Campo et al., 2000; Baker e Günther, 2004). $\mathrm{O}$ grande interesse na aplicação de produtos provenientes de algas marinhas na formulação de drogas e alimentos é também devido à composição lipídica diversificada de ácidos graxos poliinsaturados (Elenkov et al., 1996; Gill e Valivety, 1997; Medina et al., 1998). Além disso, os 
lipídios de microalgas são quimicamente similares aos óleos vegetais, tornando-os fontes potenciais para a produção de biodiesel a partir da transesterificação do óleo (Chisti, 2007; Chiu et al., 2009; Tang et al., 2010) ou óleo combustível através da liquefação direta da massa de células de microalgas (Francisco et al., 2010; Johnson e Admassu, 2013; Yeh et al., 2013).

Entre as microalgas marinhas, células da espécie Dunaliella são conhecidas por sintetizar quantidades significativas de carotenoides e lipídios em cultivos submetidos a condições de estresse salino e luminoso. É esperado algum efeito do aumento da salinidade sobre o metabolismo destes microrganismos, especialmente sobre constituintes importantes da membrana celular tais como os lipídios (Elenkov et al., 1996). Um aumento na composição lipídica da microalga $D$. tertiolecta foi reportado como sendo resposta ao aumento da salinidade ambiental (Takagi et al., 2006). Por sua vez, o acúmulo de carotenoides pode ser uma resposta ao estresse oxidativo produzido pelo excesso de luz. Os carotenoides são reconhecidos como antioxidantes eficazes contra o dano oxidativo, pois são capazes de eliminar formas radicais de oxigênio ativo, protegendo as células contra um excesso de luminosidade (Orosa et al., 2000; Hu et al., 2008; Mogedas et al., 2009).

As condições de estresse normalmente não coincidem com as condições ótimas de crescimento da maioria das microalgas, diminuindo suas taxas de crescimento (Chen et al., 2011). Além disso, a combinação de parâmetros ambientais e a configuração do sistema de produção das microalgas a fim de produzir uma densidade celular elevada e considerável conteúdo lipídico e de carotenoides são bastante complexos (Tang et al., 2010). Neste contexto, o objetivo principal deste trabalho é elucidar o efeito da intensidade luminosa e da salinidade do meio no acúmulo de carotenoides e lipídios pela microalga $D$. tertiolecta cultivada em fotobiorreator airlift. A fim de minimizar a influência destes parâmetros sobre a redução na produção de biomassa, os cultivos foram realizados em duas fases: nas primeiras $140 \mathrm{~h}$ o crescimento das células ocorreu nas condições ideais de crescimento e, posteriormente foram aplicadas condições de estresse salino e luminoso até o final dos cultivos.

\section{MATERIAIS E MÉTODOS}

\subsection{Microrganismo e Meio de Cultivo}

O microrganismo utilizado neste estudo foi a microalga unicelular Dunaliella tertiolecta, cedida pelo professor Sérgio Lourenço do Laboratório de Fisiologia e Cultivo de Algas do Departamento de Biologia Marinha da Universidade Federal Fluminense (Rio de Janeiro / Brasil).

As células foram cultivadas no meio Guillard f/2 (Guillard, 1975) modificado, consistindo de água destilada, $34 \mathrm{~g} \mathrm{~L}^{-1}$ de sal marinho (Red Sea), 16,5 $\mathrm{g} \mathrm{L}^{-1} \mathrm{NaCl}, 300 \mathrm{mg} \mathrm{L}^{-1} \mathrm{NaNO}_{3}, 5 \mathrm{mg} \mathrm{L}^{-}$ ${ }^{1} \mathrm{NaH}_{2} \mathrm{PO}_{3} \cdot \mathrm{H}_{2} \mathrm{O}, 30 \mathrm{mg} \mathrm{L}-1 \mathrm{Na}_{2} \mathrm{SiO}_{3} .9 \mathrm{H}_{2} \mathrm{O}, 1 \mathrm{~mL} \mathrm{~L}^{-1}$ solução de metais traço com $9,8 \mathrm{mg} \mathrm{L}^{-1}$ $\mathrm{CuSO}_{4} .5 \mathrm{H}_{2} \mathrm{O}, 22 \mathrm{mg} \mathrm{L}^{-1} \mathrm{ZnSO}_{4} .7 \mathrm{H}_{2} \mathrm{O}, 10 \mathrm{mg} \mathrm{L}^{-1} \mathrm{CoCl}_{2} \cdot 6 \mathrm{H}_{2} \mathrm{O}, 180 \mathrm{mg} \mathrm{L}^{-1} \mathrm{MnCl}_{2} .4 \mathrm{H}_{2} \mathrm{O}, 6,3 \mathrm{mg}$ $\mathrm{L}^{-1} \mathrm{Na}_{2} \mathrm{MoO}_{4} \cdot 4 \mathrm{H}_{2} \mathrm{O}, 4,36 \mathrm{mg} \mathrm{L}^{-1} \mathrm{Na}_{2}$ EDTA e $3,15 \mathrm{mg} \mathrm{L}^{-1} \mathrm{FeCl}_{3} \cdot 6 \mathrm{H}_{2} \mathrm{O}, 1 \mathrm{~mL} \mathrm{~L}^{-1}$ de solução de vitaminas com $100 \mathrm{mg} \mathrm{L}^{-1}$ Tiamina, $0,5 \mathrm{mg} \mathrm{L}^{-1}$ Cianocobalamina e $0,5 \mathrm{mg} \mathrm{L}^{-1}$ Biotina. $\mathrm{O} \mathrm{pH}$ do meio foi ajustado para 7,2 pela adição de $40 \mathrm{mM}$ de Tris (2-amino-2-[hidroximetil]-1-3propanediol). $\mathrm{O}$ meio de cultivo foi esterilizado em autoclave a $\left(121{ }^{\circ} \mathrm{C} / 15 \mathrm{~min}\right)$, exceto a solução de vitaminas que foi esterilizada por microfiltração $(0,22 \mu \mathrm{m}$, Millipore, Barueri, Brasil).

As microalgas foram mantidas no meio de cultivo Guillard f/2 (Guillard, 1975) a 
temperatura controlada $\left(20{ }^{\circ} \mathrm{C}\right)$ e com fotoperíodo de $12 \mathrm{~h}$ fornecido por lâmpada eletrônica de $30 \mathrm{~W}$, correspondente a uma intensidade luminosa de aproximadamente 5,8 klx.

\subsection{Experimentos em Fotobiorreator}

A fim de obter um volume de $200 \mathrm{~mL}$ de cultura para inocular os fotobiorreatores, uma alíquota de $20 \mathrm{~mL}$ de microalgas da cultura mãe do banco de cultivo foi inoculada em $180 \mathrm{~mL}$ de meio de cultivo estéril em frascos Erlenmeyer de $500 \mathrm{~mL}$. Estes frascos foram colocados em incubadora com agitação orbital com temperatura controlada de $28 \pm 1{ }^{\circ} \mathrm{C}$ e iluminação permanente através de lâmpada eletrônica de $30 \mathrm{~W}$, correspondente a uma intensidade luminosa de aproximadamente 5,8 klx, durante 12 dias. Após este período, os pré-inóculos foram considerados prontos para serem utilizados nos fotobiorreatores.

Os cultivos foram realizados em fotobiorreatores de placa do tipo airlift (Kochem et al., 2014), confeccionados em acrílico, com $450 \mathrm{~mm}$ de altura, $108 \mathrm{~mm}$ de largura, $30 \mathrm{~mm}$ de profundidade do riser, $20 \mathrm{~mm}$ de profundidade do downcomer e com volume útil de 2,2 L.

Para realizar a limpeza/assepsia dos reatores, os mesmos foram totalmente preenchidos com água destilada e $10 \mathrm{~mL}$ de solução comercial de hipoclorito de sódio (2,5\%). Após $15 \mathrm{~min}$, foram adicionados $2,5 \mathrm{~mL}$ de solução de tiossulfato de sódio $250 \mathrm{~g} \mathrm{~L}^{-1}$ para a completa neutralização do cloro. Após $2 \mathrm{~h}$ esta solução foi descartada e os reatores foram preenchidos com 2,0 L de meio de cultura estéril.

Os pré-inóculos $(200 \mathrm{~mL})$ foram inoculados nos fotobiorreatores, totalizando um volume de 2,2 L. A temperatura dos cultivos foi mantida constante em $28{ }^{\circ} \mathrm{C}$ através da passagem de água de banhos térmicos conectados por mangueiras a camisa interna de aquecimento/resfriamento de cada fotobiorreator, com área de $635 \mathrm{~cm}^{2}$. A aeração foi realizada com vazão $0,5 \mathrm{~L} \mathrm{~min}^{-1}$ de uma mistura de ar comprimido e $\mathrm{CO}_{2}$ filtrados com membrana de 0,22 $\mu$ m (Midisart@2000 / Sartorius Stedim Biotech) utilizando-se duas pedras porosas conectadas em mangueiras inseridas pelo topo dos reatores até o fundo dos mesmos. As vazões da mistura ar- $\mathrm{CO}_{2}$ foram controladas utilizandose rotâmetros (Dwyer). A quantidade de $\mathrm{CO}_{2}$ adicionada ao ar comprimido variou entre 1 e $2 \%$ a fim de manter o pH da cultura entre 7,5 e 8,5 durante todo o cultivo. Os fotobiorreatores foram iluminados continuamente na seção riser a $17,5 \mathrm{klx}$ por um painel de lâmpadas eletrônicas $(24 \times$ $13 \mathrm{~W}$, luz branca, Tashibra).

Os experimentos foram realizados em duplicata totalizando oito cultivos realizados simultaneamente. Nos cultivos submetidos ao estresse salino, uma solução concentrada de $\mathrm{NaCl}$ (5,0 M) foi adicionada no final da fase log, após 140 h de cultivo. Nesse mesmo tempo (140 h), também foi aumentada a intensidade luminosa na seção riser nos cultivos submetidos ao estresse luminoso. Portanto, após $140 \mathrm{~h}$, dois cultivos continuaram sendo realizados nas mesmas condições, sem adição de $\mathrm{NaCl}$ e aumento da intensidade de luz $(0,715 \mathrm{M} \mathrm{NaCl}$ e 17,5 klx). Após o mesmo intervalo de tempo, outros dois cultivos foram submetidos apenas ao estresse salino $(1,215 \mathrm{M} \mathrm{NaCl}$ e 17,5 klx), mais dois cultivos foram submetidos apenas ao estresse luminoso $(0,715 \mathrm{M} \mathrm{NaCl}$ e $30 \mathrm{klx})$ e dois cultivos foram submetidos ao estresse salino e luminoso $(1,215 \mathrm{M}$ $\mathrm{NaCl}$ e $30 \mathrm{klx}$ ).

A temperatura dos cultivos foi monitorada com termômetros de mercúrio e a intensidade luminosa com auxílio de um luxímetro digital (MS6610, Akso, Brazil). O pH foi medido através 
de fita indicadora de $\mathrm{pH}$ (AlkalitßMerck, Alemanha). O crescimento das microalgas foi acompanhado através de medidas de densidade ótica a $750 \mathrm{~nm}$ com espectrofotômetro Amersham Biosciences modelo Ultrospec 3100 Pro e relacionadas com biomassa por medida de peso-seco.

As medidas de temperatura, intensidade luminosa, $\mathrm{pH}$ e densidade ótica foram realizadas duas vezes ao dia com intervalos aproximados de $12 \mathrm{~h}$. Além disso, nestes mesmos intervalos, foram retiradas duas alíquotas de $2 \mathrm{~mL}$ de cada fotobiorreator, uma para a realização de medidas da densidade ótica $(750 \mathrm{~nm})$ dos cultivos e outra para análise de nitrogênio do meio de cultura e de carotenoides sintetizados pelas células. Essa última alíquota foi centrifugada $(16000 \times \mathrm{g} / 5 \mathrm{~min}) \mathrm{e}$ o sobrenadante (meio de cultura) foi removido com auxílio de uma pipeta Pasteur. O sobrenadante e o precipitado (pellet) foram congelados separadamente para determinação de nitrogênio e carotenoides totais respectivamente.

A duração média de cada cultivo foi de 210 h. Finalizados os cultivos, as células de cada fotobiorreator foram separadas do meio de cultura por centrifugação e posterior liofilização. Amostras do material liofilizado obtido em cada experimento foram utilizadas para determinação do teor de lipídios totais em extrator Soxhlet.

Os resultados foram submetidos à análise de variância (ANOVA) e as médias forma comparadas pelo teste de Tukey utilizando o software Statistica 12 (StatSoft Inc., Tulsa, EUA).

\subsection{Análises da Biomassa}

O teor de lipídios totais na biomassa foi determinado por diferença após extração com éter de petróleo $\left(135^{\circ} \mathrm{C}\right)$ utilizando-se extrator Soxhlet (Foss/Soxtec 2055TM).

O teor de carotenoides totais foi determinado por espectrofotometria. Em tubos de ensaio, 2,0 $\mathrm{mL}$ de acetona (Synth) foram adicionados ao precipitado de microalgas (descongelado). Após $12 \mathrm{~h}$ em refrigerador $\left(-4^{\circ} \mathrm{C}\right)$, o material foi centrifugado $(16000 \times g / 5 \mathrm{~min})$. Com o auxílio de uma pipeta Pasteur, o extrato (sobrenadante) foi transferido para uma cubeta de vidro. Foram medidas as absorbâncias (A) nos comprimentos de onda 661,6, 644,8 e $470 \mathrm{~nm}$. Medidas de turbidez foram realizadas em 750 e $520 \mathrm{~nm}$. As concentrações de clorofilas a e b $\left(C_{C h l a}\right.$ e $\left.C_{C h l b}\right)$ e a concentração de carotenoides totais das células $\left(C_{C t}\right)$ foram calculadas com as Equações 1, 2 e 3 (Lichtenthaler e Buschmann, 2001), onde a concentração de pigmentos é dada em $\mathrm{mg} \mathrm{L}^{-1}$ de solução do extrato.

$$
\begin{aligned}
& C_{\text {Chla }}=11,24 A_{661.6}-2,04 A_{644.8} \\
& C_{C h l b}=20,13 A_{644.8}-4,19 A_{661.6} \\
& C_{C t}=\frac{1000 A_{470}-1,90 C_{C h l a}-63,14 C_{C h l b}}{214}
\end{aligned}
$$

\subsection{Análise de $\mathrm{NaNO}_{3}$ no Meio de Cultivo}

As concentrações de nitrato de sódio foram determinadas por espectrofotometria utilizandose teste colorimétrico para determinação de nitrato de sódio em água de aquário (Mydor, Ft. Lauderdale, EUA). Foram medidas as densidades óticas $(O D)$ em $517 \mathrm{~nm}$, comprimento de onda 
no qual se observou a maior absorbância do nitrato de sódio. As concentrações de $\mathrm{NaNO}_{3}$ dos meios de cultivo foram determinadas a partir de reta padrão relacionando concentrações conhecidas de $\mathrm{NaNO}_{3}$ e densidades óticas a $517 \mathrm{~nm}$.

\section{RESULTADOS E DISCUSSÕES}

A microalga $D$. tertiolecta apresenta diferentes curvas de crescimento e quantidades de

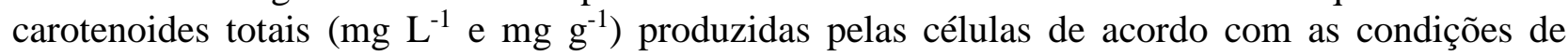
estresse salino e/ou luminoso submetidos aos cultivos (Figura 1a,c,d). O consumo de $\mathrm{NaNO}_{3}$ durante os cultivos não foi influenciado pelas diferentes condições de estresse, pois as curvas de concentração de $\mathrm{NaNO}_{3}$ em função do tempo para todos os cultivos realizados foram muito semelhantes (Figura 1b). Outros autores também não identificaram diferenças significativas nas concentrações de nitrato no decorrer dos cultivos submetidos a diferentes concentrações salinas (Takagi et al., 2006).

As condições de estresse não diminuíram a produção de biomassa quando comparados aos cultivos não submetidos a estas condições. A comparação das médias através do teste de Tukey mostrou que os valores de biomassa obtidos nas condições normais de crescimento e em condições de estresse salino e luminoso não diferem entre si após 210 h de cultivo (Tabela 1).
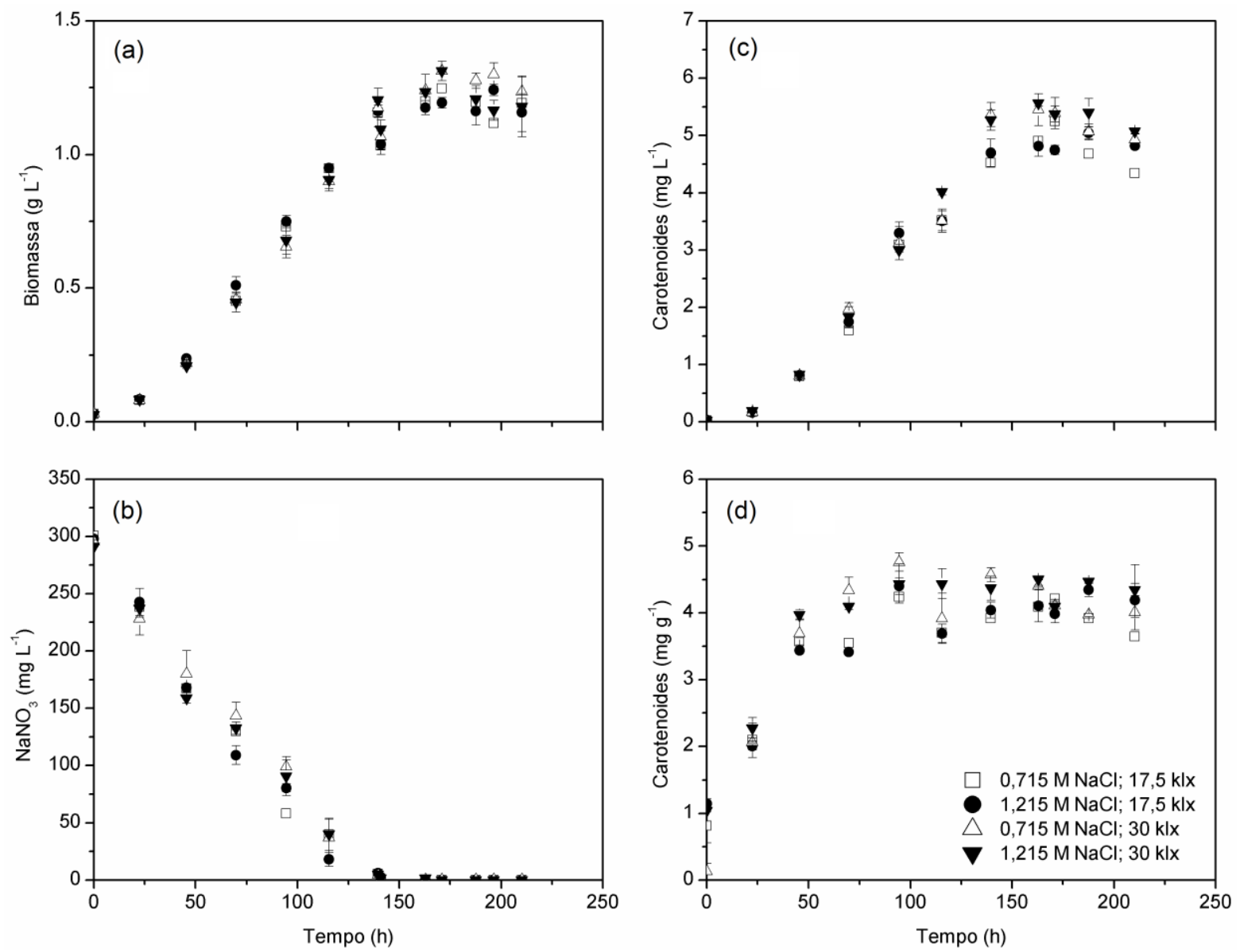

Figura 1 - (a) Biomassa, (b) consumo de nitrato de sódio, (c) concentração de carotenoides $\left(\mathrm{mg} \mathrm{L}^{-1}\right)$ e $(\mathrm{d})$ concentração de carotenoides $\left(\mathrm{mg} \mathrm{g}^{-1}\right)$ nos cultivos de Dunaliella tertiolecta em fotobiorreator airlift em condições de estresse salino e luminoso. 
Tabela 1 - Biomassa e concentrações de carotenoides e lipídios nos cultivos de Dunaliella tertiolecta em fotobiorreator airlift em condições de estresse salino e luminoso em $210 \mathrm{~h}$.

\begin{tabular}{ccccc}
\hline $\begin{array}{c}\text { Salinidade, } \\
\text { intensidade de luz } \\
(\mathrm{M} \mathrm{NaCl} ; \mathrm{klx})\end{array}$ & Biomassa & $\begin{array}{c}\text { Concentração } \\
\text { de carotenoides } \\
\left(\mathrm{mg} \mathrm{L}^{-1}\right)\end{array}$ & $\begin{array}{c}\text { Concentração } \\
\text { de carotenoides } \\
\left(\mathrm{mg} \mathrm{g}^{-1}\right)\end{array}$ & $\begin{array}{c}\text { Teor de } \\
\text { lipídios } \\
(\%)\end{array}$ \\
\hline 0,$715 ; 17,5$ & $1,19 \pm 0,00^{\mathrm{a}}$ & $4,34 \pm 0,00^{\mathrm{a}}$ & $3,64 \pm 0,00^{\mathrm{a}}$ & $8,93 \pm 0,13^{\mathrm{a}}$ \\
1,$215 ; 17,5$ & $1,16 \pm 0,07^{\mathrm{a}}$ & $4,82 \pm 0,00^{\mathrm{ab}}$ & $4,18 \pm 0,26^{\mathrm{a}}$ & $7,98 \pm 0,09^{\mathrm{b}}$ \\
0,$715 ; 30$ & $1,24 \pm 0,06^{\mathrm{a}}$ & $4,93 \pm 0,09^{\mathrm{b}}$ & $4,00 \pm 0,25^{\mathrm{a}}$ & $10,21 \pm 0,03^{\mathrm{c}}$ \\
1,$215 ; 30$ & $1,18 \pm 0,11^{\mathrm{a}}$ & $5,08 \pm 0,04^{\mathrm{b}}$ & $4,34 \pm 0,28^{\mathrm{a}}$ & $9,20 \pm 0,11^{\mathrm{a}}$ \\
\hline
\end{tabular}

A análise estatística dos dados experimentais mostrou que a iluminação e a salinidade afetam significativamente a produção de carotenoides $\left(\mathrm{mg} \mathrm{L}^{-1}\right)(p=0,028)$ e lipídios $(p<0,0001)$ pela microalga $D$. tertiolecta. Quanto maiores as condições de estresse salino e luminoso, após a fase de crescimento das microalgas, maior a síntese de carotenoides ( $\left.\mathrm{mg} \mathrm{L}^{-1}\right)$ (Figura 2a). A comparação das médias através do teste de Tukey mostrou que as quantidades de carotenoides (mg $\mathrm{L}^{-1}$ ) obtidas nos cultivos sob condições de estresse são diferentes das obtidas nas condições normais de crescimento durante todo o período (Tabela 1). Para os valores de carotenoides (mg g${ }^{1}$ ), o teste de Tukey demonstrou que os resultados obtidos não diferem entre si (Tabela 1). Com relação ao teor lipídico total, o aumento da iluminação provoca maior síntese de lipídios pela microalga $D$. tertiolecta, porém esta é diminuída com o aumento da salinidade (Figura $2 \mathrm{~b}$ ). A comparação das médias através do teste de Tukey mostrou que os valores de lipídios obtidos nas diferentes condições testadas neste trabalho diferem e entre si (Tabela 1). Outros autores também obtiveram conteúdos lipídicos mais elevados nas células de microalgas submetidas a maiores intensidades luminosas (Tang et al., 2010).
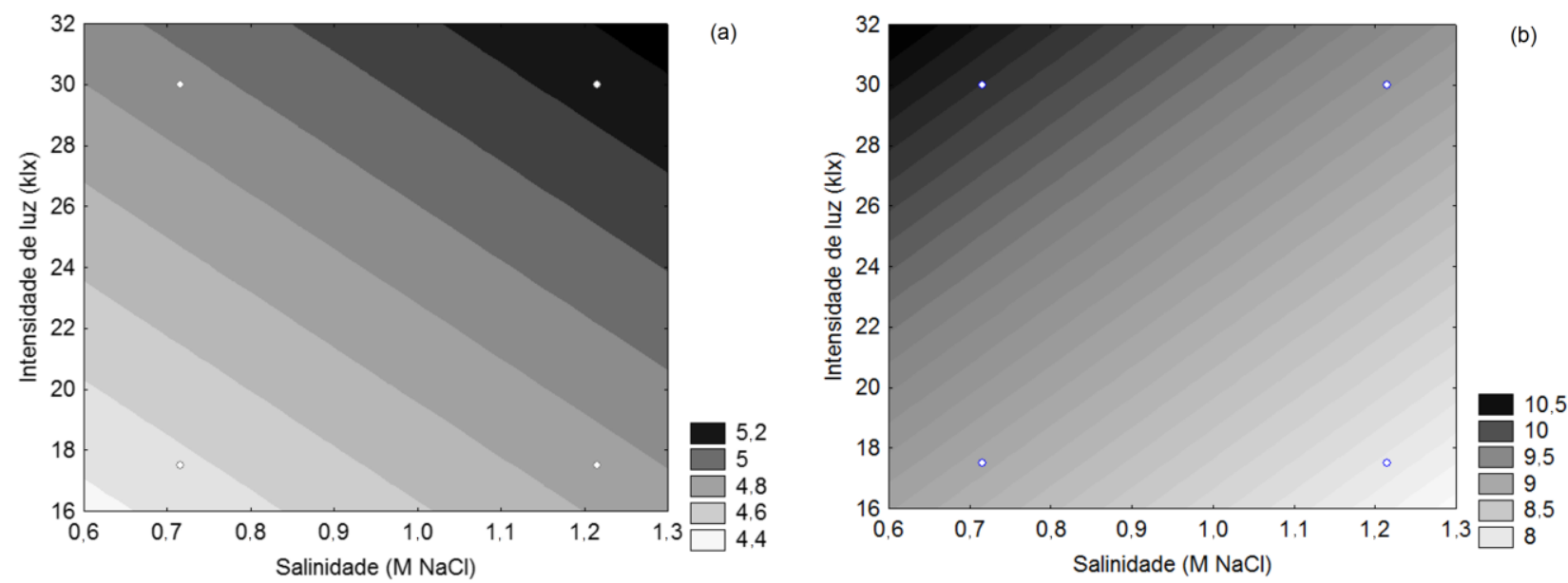

Figura 2 - Superfície de resposta da (a) concentração de carotenoides em $\left(\mathrm{mg} \mathrm{L}^{-1}\right)$ e do (b) teor de lipídios totais em $210 \mathrm{~h}$ de cultivo em função da salinidade e intensidade luminosa. 
Estudos realizados com $D$. salina demonstraram que a melhor salinidade para a obtenção de concentrações mais altas de carotenoides $\left(\mathrm{mg} \mathrm{L}^{-1}\right)$ foi $1,5 \mathrm{M} \mathrm{NaCl}$ (Farhat et al., 2011), resultado semelhante ao obtido neste trabalho, 1,215 M NaCl. Porém, os resultados obtidos por Farhat et al. (2011) demonstram que uma vez atingido o crescimento das células, um acréscimo maior de sal poderia aumentar o rendimento em carotenoides, da mesma forma como foi comprovado neste trabalho de acordo com a Figura 2a. Os autores cresceram as microalgas nas concentrações de 0,6, $1,5,3,0$ e 4,5 M NaCl durante todo o tempo de cultivo e a concentração máxima de carotenoides obtida em todos tratamentos não ultrapassou $1 \mathrm{mg} \mathrm{L}^{-1}$. A maior concentração de carotenoides obtida neste trabalho $\left(5,08 \pm 0,04 \mathrm{mg} \mathrm{L}^{-1}\right)$ pode ser atribuída a adição complementar de $\mathrm{NaCl}$ no final da fase $\log$ de crescimento das células, pois salinidades em torno de $0,5 \mathrm{M} \mathrm{NaCl}$ são consideradas mais apropriadas para a obtenção de maiores concentrações celulares da microalga D. tertiolecta (Jahnke e White, 2003).

\section{REFERÊNCIAS}

BAKER, R.; GÜNTHER, C. The role of carotenoids in consumer choice and the likely benefits from their inclusion into products for human consumption. Trends Food Sci. Tech., v. 15, n. 10, p. 484-488, 2004.

CHEN, M.; TANG, H.; MA, H.; HOLLAND, T. C.; SIMON NG, K. Y.; SALLEY, S. O. Effect of nutrients on growth and lipid accumulation in the green algae Dunaliella tertiolecta. Bioresour. Technol., v. 102, n. 2, p. 1649-1655, 2011.

CHISTI, Y. Biodiesel from microalgae. Biotechnol. Adv., v. 25, n. 3, p. 294-306, 2007.

CHIU, S.; KAO, C.; TSAI, M.; ONG, S.; CHEN, C.; LIN, C. Lipid accumulation and $\mathrm{CO}_{2}$ utilization of Nannochloropsis oculata in response to $\mathrm{CO}_{2}$ aeration. Bioresour. Technol., v. 100, n. 2, p. 833-838, 2009.

DEL CAMPO, J. A.; MORENO, J.; RODRÍGUEZ, H.; VARGAS, M. A.; RIVAS, J.; GUERRERO, M. G. Carotenoid content of chlorophycean microalgae: factors determining lutein accumulation in Muriellopsis sp. (Chlorophyta). J. Biotechnol., v. 76, n. 1, p. 51-59, 2000.

ELENKOV, I.; STEFANOV, K.; DIMITROVA-KONAKLIEVA, S.; POPOVT, S. Effect of salinity on lipid composition of Cladophora vagabunda. Phytochemistry, v. 42, n. 1, p. 39-44, 1996.

FARHAT, N.; RABHI, M.; FALLEH, H.; JOUINI, J; ABDELLY, C.; SMAOUI, A. Optimization of salt concentrations for a higher carotenoid production in Dunaliella salina (Chlorophyceae). $J$. Phycol., v. 47, n. 5, p. 1072-1077, 2011.

FRANCISCO, É. C.; NEVES, D. B.; JACOB-LOPES, E.; FRANCO, T. T. Microalgae as feedstock for biodiesel production: Carbon dioxide sequestration, lipid production and biofuel quality. J. Chem. Technol. Biotechnol., v. 85, n. 3, p. 395-403, 2010.

GILL, I.; VALIVETY, R. Polyunsaturated fatty acids, part 1: occurrence, biological activities and applications. Trends Biotechnol., v. 15, n. 10, p. 401-409, 1997.

GUILLARD, R. L. Culture of phytoplankton for feeding marine invertebrates. In: SMITH, W. e CHANLEY, M. (Ed.). Culture of marine invertebrate animals: Springer US, 1975. chap. 3, p. 2960 . 


\section{9 a 22 de outubro de 2014 \\ Florianópolis/SC}

HU, C.; LIN, J.; LU, F.; CHOU, F.; YANG, D. Determination of carotenoids in Dunaliella salina cultivated in Taiwan and antioxidant capacity of the algal carotenoid extract. Food Chem., v. 109, n. 2, p. 439-446, 2008.

INBARAJ, B. S.; CHIEN, J. T.; CHEN, B. H. Improved high performance liquid chromatographic method for determination of carotenoids in the microalga Chlorella pyrenoidosa. J. Chromatogr. A, v. 1102, n. 1-2, p. 193-199, 2006.

JAHNKE, L. S.; WHITE, A. L. Long-term hyposaline and hypersaline stresses produce distinct antioxidant responses in the marine alga Dunaliella tertiolecta. J. Plant Physiol., v. 160, n. 10, p. 1193-1202, 2003.

JOHNSON, K. R.; ADMASSU, W. Mixed algae cultures for low cost environmental compensation in cultures grown for lipid production and wastewater remediation. J. Chem. Technol. Biotechnol., v. 88, n. 6, p. 992-998, 2013.

KOCHEM, L. H.; DA FRÉ, N. C.; REDAELLI, C.; RECH, R.; MARCÍlIO, N. R. Characterization of a novel flat-panel airlift photobioreactor with an internal heat exchanger. Chem. Eng. Technol., v. 37, n. 1, p. 59-64, 2014.

LICHTENTHALER, H. K.; BUSCHMANN, C. Chlorophylls and carotenoids: measurement and characterization by UV-VIS spectroscopy. In: (Ed.). Current protocols in food analytical chemistry: John Wiley \& Sons, Inc., 2001.

MEDINA, A. R.; GRIMA, E. M.; GIMÉNEZ; A. G.; GONZÁLEZ; M. J. I. Downstream processing of algal polyunsaturated fatty acids. Biotechnol. Adv., v. 16, n. 3, p. 517-580, 1998.

MOGEDAS, B.; CASAL, C.; FORJÁN, E.; VÍLCHEZ, C. $\beta$-Carotene production enhancement by UV-A radiation in Dunaliella bardawil cultivated in laboratory reactors. J. Biosci. Bioeng., v. 108, n. 1, p. 47-51, 2009.

OROSA, M.; TORRES, E.; FIDALGO, P.; ABALDE, J. Production and analysis of secondary carotenoids in green algae. J. Appl. Phycol., v. 12, n. 3, p. 553-556, 2000.

RAJA, R.; HEMAISWARYA, S.; RENGASAMY, R. Exploitation of Dunaliella for $\beta$-carotene production. Appl. Microbiol. Biotechnol., v. 74, n. 3, p. 517-523, 2007.

TAKAGI, M.; KARSENO; YOSHIDA, T. Effect of salt concentration on intracellular accumulation of lipids and triacylglyceride in marine microalgae Dunaliella cells. J. Biosci. Bioeng., v. 101, n. 3, p. 223-226, 2006.

TANG, H.; ABUNASSER, N.; GARCIA, M. E. D.; CHEN, M.; SIMON NG, K. Y.; SALLEY, S. O. Potential of microalgae oil from Dunaliella tertiolecta as a feedstock for biodiesel. Appl. Energ., v. 88, n. 10, p. 3324-3330, 2010.

YEH, T. M.; DICKINSON, J. G.; FRANCK, A.; LINIC, S.; THOMPSON Jr, L. T.; SAVAGE, P. E. Hydrothermal catalytic production of fuels and chemicals from aquatic biomass. J. Chem. Technol. Biotechnol., v. 88, n. 1, p. 13-24, 2013. 